\title{
AVALIAÇÃO DA QUALIDADE FISIOLÓGICA DE SEMENTES FLORESTAIS ATRAVÉS DO TESTE DE CONDUTIVIDADE ELÉTRICA
}

\author{
Karina Guollo ${ }^{1}$, Jean Carlo Possenti ${ }^{1}$, Marciele Felippi ${ }^{1}$, Erci Marcos Del Quiqui ${ }^{2}$, Táscilla Magalhães Loiola ${ }^{3}$ \\ Universidade Tecnológica Federal do Paraná - UTFPR ${ }^{1 .}$ Universidade Estadual de Maringá - UEM ${ }^{2}$. Universidade \\ Estadual do Centro-Oeste - UNICENTRO3.E-mail: engkarinaguollo@hotmail.com
}

\section{RESUMO}

A avaliação da condutividade elétrica é um dos testes mais rápidos na avaliação da qualidade de sementes, assim, o objetivo foi verificar a qualidade fisiológica de sementes de oito espécies florestais por meio do teste de condutividade elétrica massal e, se este é eficiente para tal, correlacionando-o com a germinação. O delineamento foi inteiramente casualizado com 4 repetições de 25 sementes, avaliando-se os períodos de embebição $(2,4,6,8,24$ e 48 horas). Após cada período, realizou-se a leitura da condutividade, sendo que em seguida as mesmas sementes foram postas para germinar com intuito de correlacionar os valores de condutividade com a germinação. Foi realizada a análise de correlação entre condutividade elétrica e germinação dentro de cada período de embebição. O teste de condutividade elétrica massal se mostrou eficiente para avaliação da qualidade das sementes das espécies estudadas, quando comparado ao teste padrão de germinação, podendo ser uma alternativa rápida para avaliação da qualidade fisiológica de sementes florestais.

Palavras-chave: indicador bioquímico; germinação; integridade de membranas celulares.

\section{EVALUATION OF THE PHYSIOLOGICAL QUALITY OF FOREST SEEDS SPECIES THROUGH THE ELECTRICAL CONDUCTIVITY TEST}

\begin{abstract}
The evaluation of the electrical conductivity is one of the rapid tests in the assessment of quality seeds, so the goal was to evaluate the physiological quality efficiency of eight forest species seeds through the individual electrical conductivity test and the efficiency of this. The design was completely randomized with 4 replications of 25 seeds, evaluating the soaking periods (2, 4, 6, 8, 24 and 48 hours). After each period, there was the reading of conductivity, and then the seeds were germinated in order to correlate the conductivity values with germination. The test of the individual electrical conductivity was efficient to evaluate the quality of the seeds.
\end{abstract}

Keywords: biochemical indicator; germination; integrity of cell membranes.

\section{INTRODUÇÃO}

Aspidosperma parvifolium é conhecida popularmente como guatambu e Aspidosperma polyneuron conhecida como peroba-rosa pertencem a família Apocynaceae, são utilizadas principalmente na recomposição de áreas degradadas e apresentam alto valor comercial devido a qualidade da madeira (LORENZI, 2008). Segundo Lorenzi (2002) e Souza e Moscheta (1987), ambas as espécies encontram-se em extinção em diversas regiões do Brasil. Assim como Cabralea canjerana que pertence a família Meliaceae já esteve ausente nas matas de araucárias (REITZ et al., 1983) devido a sua exploração. É espécie indicada para uso em programas de recuperação de áreas degradadas e no paisagismo (PEREIRA et al., 2011). Ainda, Cariniana legalis (jequitibá) pertence a família Lecythidaceae, tem como principal atrativo sua madeira de alta qualidade e grande valor paisagístico, contudo, também se encontra na lista oficial das espécies da flora brasileira ameaçadas de extinção (CARVALHO, 2005). A espécie Gallesia integrifolia (pau-d'alho) pertence a família Phytolaccaceae possui madeira altamente apreciada e comparada ao pinheiro- 
do-paraná devido a sua durabilidade (CARVALHO, 1994), sendo utilizada em programas de reflorestamento e recuperação de áreas degradadas (FEIJÓ et al., 2009). Da mesma forma Handroanthus chrysotrichus (ipê-amarelo) pertence a família Bignoniaceae, é utilizada na recomposição de áreas de matas nativas, arborização urbana e, apresenta também alto valor comercial de sua madeira (LORENZI, 2008), principalmente para exportação. Por fim, as espécies Lonchocarpus campestris (rabo-debugio) e Pterogyne nitens (amendoim-bravo) pertencem à família Fabaceae (LORENZI, 2008), são amplamente utilizadas na recuperação de áreas degradadas e reflorestamentos por produzir anualmente grande quantidade de frutos (CARVALHO, 1994).

Além da demanda por sementes de espécies nativas para plantios em recuperações de áreas degradadas, a demanda para uso em projetos voluntários e plantios comerciais, também intensifica o mercado de produção de sementes (BRANCALION et al., 2010). Segundo Matos (2009) também há crescente demanda por métodos rápidos e eficientes para a avaliação da qualidade fisiológica de sementes florestais nativas. Contudo, muitas espécies florestais ainda possuem inúmeras limitações pela falta de conhecimento quanto às características de morfoanatomia e ecofisiologia de suas sementes.

A rapidez na avaliação da qualidade fisiológica das sementes contribui para a tomada de decisão nas etapas finais da produção, armazenamento e comercialização das mesmas. Ao optar pelo uso de testes rápidos, além do clássico teste de germinação para a avaliação da qualidade das sementes, o produtor de mudas requer a mesma confiabilidade quanto ao comportamento na semeadura (FESSEL et al., 2010).

Vários testes podem ser utilizados para avaliar o vigor e a qualidade fisiológica das sementes, dentre estes pode-se citar o teste de condutividade elétrica (CORTE et al., 2010). Segundo Marcos Filho (2015) o princípio do teste é que sementes menos vigorosas liberam mais solutos para o meio, pois a velocidade do restabelecimento das membranas durante a embebição é menor. A comparação entre os valores das leituras da liberação de solutos de diferentes lotes de sementes indica possíveis diferenças no vigor das sementes.

Apesar do teste de condutividade elétrica ter destaque como sendo um dos testes mais rápidos na avaliação da qualidade e vigor de sementes, os estudos com as espécies florestais ainda são escassos, contudo os poucos realizados (MARQUES et al., 2002; SANTOS; PAULA, 2005; GONÇALVES et al., 2008), mostram que o teste é promissor e traz inúmeros benefícios para a área de tecnologia de sementes.

Diante do exposto, conduziu-se esta investigação científica com o objetivo de verificar a possibilidade de avaliação da qualidade fisiológica das sementes de diferentes espécies florestais, pelo teste de condutividade elétrica massal de forma que o mesmo possa substituir o teste padrão de germinação com o mesmo nível de confiabilidade, visto que trabalhos com as espécies em questão neste nível ainda são inexistentes na literatura.

\section{MATERIAL E MÉTODOS}

O material experimental foi composto por sementes das espécies florestais: Aspidosperma parvifolium (guatambu); Aspidosperma polyneuron (peroba-rosa); Cabralea canjerana (canjerana); Cariniana legalis (jequitibá); Gallesia integrifolia (pau-d'alho); Handroanthus chrysotrichus (ipê-amarelo); Lonchocarpus campestris (rabo-de-bugio) e; Pterogyne nitens (amendoim-do-campo). As sementes foram coletadas de árvores matrizes localizadas no Estado do Paraná, em áreas de preservação permanente ou em pequenos remanescentes florestais.

As condições nas quais conduziram-se os testes de condutividade elétrica (quantidade de sementes, quantidade de água e temperatura) foram definidas a partir de estudos realizados publicados pela AOSA $(1983 ; 2002)$ e realizados por Santos e Aguiar (2005) e Flavio e Paula (2010). Dessa forma, foram utilizadas 4 repetições de 25 sementes, as quais foram pesadas e postas em recipientes contendo $75 \mathrm{~mL}$ de água destilada, alocados em câmara germinadora tipo BOD com temperatura constante de $25{ }^{\circ} \mathrm{C}$ durante seis períodos de embebição (2, 4, 6, 8, 24 e 48 horas).

Após cada período de embebição, realizou-se a leitura da condutividade elétrica da solução na qual as sementes estavam imersas, utilizando-se um condutivímetro digital de bancada Mod CG 2000, com precisão de \pm 1 , cujos resultados de leitura (diminuído do valor de condutividade elétrica de água pura) foram divididos pelos respectivos valores de massa das amostras das sementes, sendo os resultados 
expressos em $\mu \mathrm{S} \cdot \mathrm{cm}^{-1} \cdot \mathrm{g}^{-1}$ de semente. Logo após a leitura, as mesmas sementes foram colocadas para germinar com o intuito de se correlacionar o valor de condutividade elétrica com o percentual germinativo.

Para os testes de germinação foram utilizadas sementes sem procedimentos de assepsia e, condições estabelecidas por Martins et al. (2011) e Fantinel et al. (2013) para Handroanthus chrysotrichus; Kopper et al. (2010) para Cariniana legalis; Carvalho et al. (2006) para Aspidosperma polyneuron; Silva et al. (2007) para Aspidosperma parvifolium, Santos et al. (2008) para Pterogyne nitens; Barros et al. (2005) para Gallesia integrifolia; Lima et al. (2008) para Lonchocarpus campestris; e Grunennvaldt et al. (2014) para Cabralea canjerana. Quando não disponíveis para a mesma espécie, adotou-se o recomendado para o mesmo gênero.

As condições comumente encontradas para a germinação foram sob temperatura de $25{ }^{\circ} \mathrm{C}$ com fotoperíodo de 12 horas de luz e 12 horas de escuro, utilizando-se o substrato rolo de papel, com exceção da espécie Cabralea canjerana que foi acondicionada no substrato sobre papel, em condição de escuro contínuo, pois possui comportamento fotoblástico negativo (GRUNENNVALDT et al., 2014).

Todos os substratos foram previamente esterilizados em autoclave vertical e para o teste de germinação foram umedecidos com água destilada, na quantidade equivalente a 2,5 vezes a massa seca do substrato, conforme determina as Regras de Análises de Sementes - RAS (BRASIL, 2009). Todos os testes foram alocados em câmara tipo B.O.D. (Biological Demand Oxigen).
A germinação foi calculada pela formula $G \%=(N / 100) \times 100$, em que: $N=$ número de sementes germinadas ao final do teste. Foram consideradas germinadas as sementes que atenderam o critério botânico de germinação, definido pela emissão da raiz primária, segundo Santos e Aguiar (2005).

$O$ delineamento utilizado foi inteiramente casualizado, em um modelo unifatorial para os tratamentos (períodos de embebição: 2, 4, 6, 8, 24 e 48 horas) com 4 repetições de 25 sementes.

Após a compilação, o conjunto de dados foi submetido ao teste homogeneidade da variância (Bartlett) e normalidade dos dados (Lilliefors), logo, atendidas as pressuposições do modelo, procedeu-se a análise estatística.

Foi realizada a análise de correlação entre condutividade elétrica e germinação dentro de cada período de embebição. A interpretação do coeficiente de correlação se deu conforme apontado por Dancey e Reidy (2006), onde: $r=0$ indica que não há relação linear entre as variáveis; $r=0,10$ até 0,30 corresponde a uma correlação fraca; $r=0,40$ até 0,60 à correlação moderada; $r=0,70$ até 1 , à correlação forte (para ambos os casos, negativa ou positiva). Os testes aplicados foram considerados eficientes quando a correlação entre condutividade elétrica e germinação foi classificada como forte.

\section{RESULTADOS E DISCUSSÃO}

Como mostra a Tabela 1, os diferentes períodos de embebição das sementes resultaram em diferentes leituras de condutividade elétrica para todas as espécies estudadas, portanto, rejeitou-se a hipótese de nulidade $\left(H_{0}\right)$.

Tabela 1. Coeficiente de variação, Teste $F$, condutividade elétrica média (CE) e germinação (G) para o teste de condutividade elétrica massal em função de diferentes períodos de embebição de sementes florestais.

\begin{tabular}{lcccc}
\hline \multicolumn{1}{c}{ Espécie } & $\mathrm{CV}(\%)$ & $\mathrm{F}$ & $\begin{array}{c}\mathrm{CE}\left(\mu \mathrm{S} . \mathrm{cm}^{-1} \cdot \mathrm{g}^{-1} \mathrm{de}\right. \\
\mathrm{semente})\end{array}$ & $\mathrm{G}(\%)$ \\
\hline Aspidosperma parvifolium & 6,7 & $33,99^{* *}$ & 182 & 65 \\
Aspidosperma polyneuron & 17,8 & $26,06^{* *}$ & 229 & 37 \\
Cabralea canjerana & 15,2 & $51,48^{* *}$ & 131 & 18 \\
Cariniana legalis & 8,2 & $152,38^{* *}$ & 42 & 58 \\
Gallesia integrifolia & 8,3 & $189,13^{* *}$ & 471 & 46 \\
Handroanthus chrysotrichus & 3,6 & $150,83^{* *}$ & 342 & 24 \\
Lonchocarpus campestris & 13,4 & $13,76^{* *}$ & 137 & 60 \\
Pterogyne nitens & 12,1 & $50,27^{* *}$ & 254 & 34 \\
\hline
\end{tabular}

\footnotetext{
**significativo ao nível de $1 \%$ de probabilidade $(\mathrm{p}<0,01) ;$ *significativo ao nível de $5 \%$ de probabilidade $(0,01$
} $=<p<0,05) ; n s=$ não significativo; CV = coeficiente de variação; $F=$ estatística do teste $F$. 
Ainda na Tabela 1, nota-se que para todas as espécies foram encontrados baixos valores de coeficiente de variação, mostrando bom controle experimental. Ainda, pode-se que para Cariniana legalis a CE foi inferior em relação às leituras obtidas com as demais espécies, possivelmente por possuir pericarpo mais espesso e resistente, diminuindo e liberação de solutos para o meio. Ao contrário do obtido em sementes de Gallesia integrifolia a qual, libera grande quantidade de solutos.

A Tabela 2 mostra os coeficientes de correlação entre condutividade elétrica e germinação pelo método massal em diferentes períodos de embebição das sementes. Valores próximos a menos um (-1) significam alto grau de associação entre as variáveis, o que ajuda na determinação do período em que a condutividade elétrica deve ser conduzida.

Tabela 2. Coeficientes de correlação ( $r$ ) entre condutividade elétrica e germinação pelo método massal em diferentes períodos de embebição de sementes.

\begin{tabular}{ccccccc}
\hline Tempo & 2 horas & 4 horas & 6 horas & 8 horas & 24 horas & 48 horas \\
\cline { 1 - 5 } Espécie & & & & & & $-0,41$ \\
A. parvifolium & $-0,33$ & $-0,01$ & $-0,84$ & $-0,50$ & $-0,55$ \\
A. polyneuron & $-0,11$ & $-0,10$ & $-0,38$ & $-0,82$ & 0,92 & 0,20 \\
C. canjerana & 0,98 & 0 & $-0,21$ & $-0,75$ & $-0,73$ & 0 \\
C. legalis & 0,86 & 0,69 & 0,23 & $-0,20$ & $-0,84$ & $-0,55$ \\
G. integrifolia & 0,52 & 0,33 & 0,58 & 0,70 & 0,23 & $-0,44$ \\
H. chrysotrichus & $-0,33$ & 0,42 & 0,32 & $-0,81$ & $-0,51$ & 0 \\
L. campestris & $-0,68$ & $-0,26$ & $-0,63$ & $-0,38$ & $-0,94$ & 0,95 \\
P. nitens & $-0,71$ & $-0,05$ & 0,64 & $-0,49$ & $-0,63$ & $-0,89$ \\
\hline
\end{tabular}

Nota-se que para Aspidosperma parvifolium e Aspidosperma polyneuron o período que melhor pode-se correlacionar a condutividade elétrica com a germinação foi de 8 horas de embebição. Resultado superior foi encontrado por Santos e Paula (2005), que recomendaram o período de 24 horas de embebição para leitura da condutividade elétrica de sementes de Sebastiania commersoniana.

Para a espécie Cabralea canjerana se destacaram os períodos de 8 e 24 horas de embebição das sementes. Resultado diferente foi encontrado por Baldo (2012) avaliando os períodos de 2, 4, 6, 12, 24, 48, 96 e $120 \mathrm{~h}$ de embebição em sementes de $C$. fissilis. $O$ autor verificou que, com duas horas de embebição já é possível a diferenciação dos lotes de sementes para a espécie.

Sementes de Cariniana legalis mostraram uma correlação forte com 24 horas de embebição, contudo, em trabalho realizado por Kopper (2008) estudando o teste de condutividade elétrica para sementes de Cariniana estrellensis, recomendou a embebição das sementes por 48 horas, sendo que este período foi eficiente na classificação dos lotes quanto ao vigor.

Para Gallesia integrifolia o melhor período de embebição foi de 48 horas, porém apresentando uma correlação moderada, contraditoriamente ao encontrado por Gonçalves (2012) em sementes de Phytolacca dioica, o qual verificou que o melhor período de embebição de sementes foi por 24 horas, sendo suficiente para avaliação da qualidade fisiológica das mesmas.

As sementes de Handroanthus chrysotrichus apresentaram melhor correlação entre condutividade elétrica e germinação no período de 8 horas de embebição, apresentando uma correlação forte. Segundo Gonzales e Valeri (2011) estudando sementes de Zeyheria tuberculosa, o teste de condutividade elétrica aplicado pelo período de 24 horas é eficiente para avaliação da qualidade fisiológica das sementes. O teste de condutividade elétrica massal também foi utilizado por Fonseca et al. (2005), na avaliação de sementes de Tabebuia chrysotricha (sinonímia Handroanthus), em que os resultados de CE se correlacionaram com os do teste de germinação. Os autores submeteram as 
sementes a um período de embebição de 24 horas para posterior leitura da condutividade.

Para Lonchocarpus campestris o melhor período observado para embebição das sementes no presente trabalho foi de 24 horas, mostrando uma correlação forte. Entretanto, resultado diferente e superior foi encontrado por Marques et al. (2002) que confirmam que o teste de condutividade elétrica massal é eficiente na diferenciação de lotes de sementes de Dalbergia nigra, apresentando alta correlação com a germinação, sendo que o melhor período de embebição para as sementes foi de 30 ou 36 horas. Esse resultado foi superior ao encontrado no presente trabalho para sementes de Lonchocarpus campestris, pertencente à mesma família.

Para a espécie Pterogyne nitens o período de 2 e 48 horas foi eficiente para avaliação da qualidade das sementes, mostrando uma correlação forte. Para sementes da mesma espécie, Ataide et al. (2012), recomendaram o teste de condutividade elétrica massal considerando um tempo de embebição de 24 horas.

Os diferentes períodos de embebição que se adequam para cada espécie podem ser justificados por diversos fatores. Dentre estes fatores podemos citar as características morfológicas do tegumento das sementes e por

\section{REFERÊNCIAS}

AOSA. Seed vigor handobook. In: The handbook of seed testing. East Lansing, 1983. 88p.

AOSA. Seed vigor testing handbook. Lincoln, 2002. 105p.

ATAIDE, G.M.; FLORES, A.V.; BORGES, E.E.L.; RESENDE, R.T. Adequação da metodologia do teste de condutividade elétrica para sementes de Pterogyne nitens Tull. Revista Brasileira de Ciências Agrárias, v.7, n.4, p.635-640, 2012. https://doi.org/10.5039/agraria.v7i4a1688

BALDO, T. Desempenho e caracterização de sementes de diferentes procedências de Cedrela fissilis Velozzo. 2012. 63 f. Dissertação (Mestrado). Universidade Estadual Paulista Júlio de Mesquita Filho, Jaboticabal.

BARROS, S.S.U.; SILVA, A.; AGUIAR, I.B. Germinação de sementes de Gallesia integrifolia consequência o padrão de absorção de água que obedecem durante a embebição, o que vem exercer influência sobre o fluxo de solutos das sementes para o meio de embebição e por fim nas leituras da condutividade elétrica do meio (POWELL, 1998).

Resultados de ensaios realizados com outras espécies, mostram o quanto são escassos trabalhos com sementes florestais e a amplitude das análises realizadas. Apesar da eficiência encontrada para o método, novos estudos devem ser realizados para aprimorar a precisão do teste para as espécies analisadas, tendo em vista que diversos fatores podem influenciar sua eficiência, como o tempo de embebição e a temperatura a qual o teste é exposto que também foram abordadas em outros estudos, pelo fato de influenciarem no padrão de lixiviação de sementes.

\section{CONCLUSÕES}

O teste de condutividade elétrica massal se mostrou eficiente para avaliação da qualidade das sementes das espécies estudadas, quando comparado ao teste padrão de germinação, podendo ser alternativa rápida para avaliação da qualidade fisiológica de sementes florestais fornecendo informações precisas quanto ao seu desempenho.

(Spreng.) Harms (pau-d'alho) sob diferentes condições de temperatura, luz e umidade do substrato. Revista Brasileira de Botânica, v.28, n.4, p.727-733, 2005. https://doi.org/10.1590/S010084042005000400007

BRANCALION, P.H.S.; RODRIGUES, R.R.; GANDOLFI, S.; KAGEYAMA, P.Y.; NAVE, A.G.; GANDARA, F.B.; BARBOSA, L.M.; TABARELLI, M. Instrumentos legais podem contribuir para a restauração de florestas tropicais biodiversas. Revista Árvore, v.34, n.3, p.455-470, 2010. https://doi.org/10.1590/S0100$\underline{67622010000300010}$

BRASIL. Ministério da Agricultura, Pesca e Abastecimento. Regras para análise de sementes. Secretaria Nacional de Defesa Agropecuária. Brasília, 2009. 399 p. 
CARVALHO, P.E.R. Espécies florestais brasileiras: recomendações silviculturais, potencialidades e uso da madeira. Colombo: EMBRAPA-CNPF, 1994. p. 79-84.

CARVALHO, P.E.R. Jequitibá-rosa. Circular Técnica. Embrapa Florestas. Colombo-

PR. n 107, 10 p., 2005.

CARVALHO, L.R.; SILVA, E.A.A.; DAVIDE, A.C. Classificação de sementes florestais quanto ao comportamento no armazenamento. Revista Brasileira de Sementes, v.28, n.2, p.15-25, 2006. https://doi.org/10.1590/S0101$\underline{31222006000200003}$

CORTE, V.B.; BORGES, E.E.L.; LEITE, H.G.; LEITE, I.T.A. Qualidade fisiológica de sementes de Melanoxylon brauna envelhecidas natural e artificialmente. Scientia Forestalis, v.38, n.86, p.181-189. 2010.

DANCEY, C.; REIDY, J. Estatística sem matemática para psicologia: usando SPSS para Windows. Porto Alegre: Artmed, 2006.

FANTINEL, V.S., OLIVEIRA, L.M., MUNIZ, M.F.B., ROCHA, E.C. Deteç̧ão de fungos e transmissão de Alternaria alternata via sementes de ipê-amarelo, Handroanthus chrysotrichus Mattos. Revista de Ciências Ambientais, v.7, n.2, p.05-14, 2013.

FEIJÓ, N.S.A.; MIELKE, M.S.; GOMES, F.P.; FRANÇA, S.; LAVINSKY, A.O. Growth and photosynthetic responses of Gallesia integrifolia (Spreng.) Harms and Schinus terebinthifolius Raddi seedlings in dense shade. Agroforestry Systems, v.77, p. 49-58, 2009. https://doi.org/10.1007/s10457-008-9190-x

FESSEL, S.A.; PANOBIANCO, M.; SOUZA, C.R.; VIEIRA, R.D. Teste de condutividade elétrica em sementes de soja armazenadas sob diferentes temperaturas. Bragantia, v.69, n.1, p.207-214, $2010 . \quad$ https://doi.org/10.1590/S0006$\underline{87052010000100026}$

FLAVIO, J.J.P.; PAULA, R.C. Testes de envelhecimento acelerado e de condutividade elétrica em sementes de Dictyoloma vandellianum A. Juss. Scientia Forestales, v.38, n.87, p.391-399, 2010.
FONSECA, R.L.; MENEGARIO, C.; MORI, E.S.; NAKAGAWA, J. Maturidade fisiológica das sementes de ipê amarelo, Tabebuia chrysotricha (Mart. Ex DC.) Standl. Scientia Forestalis, v.33, n.69, p.136-141, 2005.

GONÇALVES, E.P.; Paula, R.C.; DESMATLÊ, M.E.S.P. Testes de vigor em sementes de Guazuma ulmifolia Lam. Semina: Ciências Agrárias, v.29, p.265-276, 2008. https://doi.org/10.5433/1679$\underline{0359.2008 v 29 n 2 p 265}$

GONÇALVES, L.P. Morfologia, Germinação, Armazenamento, Vigor e Sanidade de Sementes de Phytolacca dioica Linnaeus. 2012. 96p. Dissertação (Mestrado). Universidade Federal do Paraná, Curitiba, 2012.

GONZALES, J.L.S.; VALERI, S.V. Prueba de La conductividad eléctrica em La evaluación fisiológica de La calidad de semillas em Zeyheria tuberculosa. Bosque, v.32, n.2, p.197-202, 2011. https://doi.org/10.4067/S0717-

$\underline{92002011000200010}$

GRUNENNVALDT, R.L.; CANTARELLI, E.B.; SALAMONI, A.T. Armazenamento e viabilidade de sementes de Cabralea canjerana (Vell.) Mart. Comunicata Scientiae, v.5, n.1, p.98-105, 2014.

KOPPER, A.C. Adequação de testes para avaliação da viabilidade e vigor de sementes de Cariniana estrellensis (Raddi) Kuntze. 2008. 85p. Dissertação (Mestrado). Universidade Estadual do Oeste do Paraná, Marechal Cândido Rondon, 2008.

KOPPER, A.C.; MALAVASI, M.M.; MALAVASI, U.C. Influência da temperatura e do substrato na germinação de sementes de Cariniana estrellensis (Raddi) Kuntze. Revista Brasileira de Sementes, v.32, n.2, p.160-165, 2010. https://doi.org/10.1590/S0101$\underline{31222010000200020}$

LIMA, V.V.F.; VIEIRA, D.L.M.; SEVILHA, A.C.; SALOMÃO A.N. Germinação de espécies arbóreas de floresta estacional decidual do vale do rio Paranã em Goiás após três tipos de armazenamento por até 15 meses. Biota Neotropica, v.8, n.3, 2008. https://doi.org/10.1590/S1676$\underline{06032008000300008}$ 
LORENZI, H. Árvores brasileiras: manual de identificação e cultivo de plantas arbóreas nativas do Brasil. Nova Odessa: Plantarum, 2002. p.41.

LORENZI, H. Árvores brasileiras: manual de identificação e cultivo de plantas arbóreas nativas do Brasil. Nova Odessa: Plantarum, 2008. 384 p.

MARCOS FILHO, J. Fisiologia de sementes de plantas cultivadas. Londrina: ABRATES, 2015. 659 p.

MARQUES, M.A.; PAULA, R.C.; RODRIGUES, T.J.D. Adequação do teste de condutividade elétrica para determinar a qualidade fisiológica de sementes de jacarandá-da-bahia (Dalbergia nigra (Vell.) Fr. All. ex. Benth). Revista Brasileira de Sementes, v.24, n.1, p.271-278, 2002. https://doi.org/10.1590/S0101-

$\underline{31222002000100038}$

MARTINS, L.; LAGO, A.A.; CICERO, S.M. Qualidade fisiológica de sementes de Tabebuia avellanedae e Tabebuia impetiginosa submetidas à ultra-secagem. Revista Brasileira de Sementes, v.33, n.4, 2011. https://doi.org/10.1590/S0101-

31222011000400004

MATOS, J.M.M. Avaliação do Teste do pH do exsudato na verificação de viabilidade de sementes florestais. 2009. 75p. Dissertação (Mestrado). Universidade de Brasília, Brasília, 2009.

PEREIRA, M.F.; BANDEIRA, L.F.; BLANCO, A.J.V.; COELHO, A.S.G.; CIAMPI, A.Y.; FRANCESCHINELLI, E.V. Isolation and characterization of microsatellite locis in Cabralea canjerana (Meliaceae). American Journal of Botany, v.98, n.1, p.1-3, 2011. https://doi.org/10.3732/ajb.1000336

POWELL, A.A. Seed improvement by selection and invigoration. Scientia Agricola, v.55, p.126133, 1998. https://doi.org/10.1590/S0103$\underline{90161998000500023}$
REITZ, R.; KLEIN, R.M.; REIS, A. Projeto Madeira do Rio Grande do Sul. Sellowia, v. 34/35, p. 1525, 1983.

SANTOS, M.J.C.; NASCIMENTO, A.V.S.; MAURO, R.A. Germinação do amendoim bravo (Pterogyne nitens Tul) para utilização na recuperação de áreas degradadas. Revista Brasileira de Ciências Agrárias, v.3, n.1, p.31-34, 2008. https://doi.org/10.5039/agraria.v3i1a182

SANTOS, S.R.G.; AGUIAR, I.B. Efeito da temperatura na germinação de sementes de Sebastiania commersoniana (Baillon) Smith \& Downs separadas pela coloração do tegumento. Scientia Forestalis, v.69, p.77-83, 2005.

SANTOS, S.R.G.; PAULA, R.C. Teste de condutividade elétrica para avaliação da qualidade fisiológica de sementes de Sebastiania commersoniana (BAIL) SMITH \& DOWNS Euphorbiaceae. Revista Brasileira de Sementes, v.27, n.2, p136-145, 2005.

SILVA, A.; FIGLIOLIA, M.B.; AGUIAR, I.B. Germinação de sementes de Acacia polyphylla DC. (monjoleiro) e de Aspidosperma ramiflorum Müll. Arg. (guatambu). Revista Floresta, v.37, n.3, $2007 . \quad$ https://doi.org/10.1590/S010131222005000200020

SOUZA, L.A. de.; MOSCHETA, I.S. Morfo-anatomia do desenvolvimento do fruto e da plântula de Aspidosperma polyneuron M. Arg. (Apocynaceae). In: CONGRESSO NACIONAL DE BOTÂNICA, 38., 1987. Resumos... São Paulo: Sociedade Botânica do Brasil / Universidade de São Paulo, 1987. p. 345.

Recebido para publicação em 04/09/2016

Revisado em 13/12/2016

Aceito em 03/04/2017 